
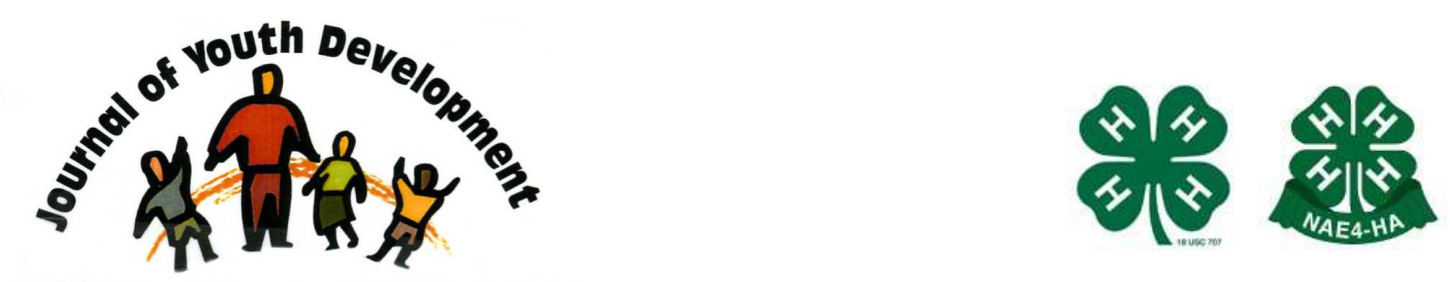

Bridging Research \& Practice

\title{
Positive Youth Development: Processes, Programs, and Problematics
}

\author{
Richard M. Lerner \\ Tufts University \\ richard.lerner@tufts.edu \\ Jacqueline V. Lerner \\ Boston College \\ Selva Lewin-Bizan \\ Tufts University \\ Edmond P. Bowers \\ Tufts University \\ Michelle J. Boyd \\ Tufts University \\ Megan Kiely Mueller \\ Tufts University \\ Kristina L. Schmid \\ Tufts Unversity \\ Christopher M. Napolitano \\ Tufts University
}




\title{
JOURNAL OF YOUTH DEVELOPMENT \\ bridging research and practice

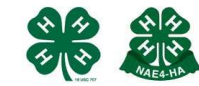

Volume 6, Number 3, Fall 2011

Article 110603FA003

\section{Positive Youth Development: Processes, Programs, and Problematics}

Richard M. Lerner, Jacqueline V. Lerner, Selva Lewin-Bizan, Edmond P. Bowers, Michelle J. Boyd, Megan Kiely Mueller, Kristina L. Schmid and Christopher M. Napolitano

\begin{abstract}
Using the tripartite conception of positive youth development (PYD) suggested by Hamilton (1999) - as a developmental process, a philosophy or approach to youth programming, and as instances of youth programs and organizations focused on fostering the healthy or positive development of youth - we review different theoretical models of the developmental process involved in PYD. In addition, we review the ideas for and the features of youth development programs aimed at promoting PYD. We discuss the need for research interrelating different, theoretically-predicated measures of PYD and, as well, the importance of clear links between models of the PYD developmental process and of the youth development programs seeking to enhance PYD among diverse youth. We discuss several conceptual and practical problematics that must be addressed in order to integrate the three facets of PYD scholarship.
\end{abstract}

\section{Introduction}

Interests in the strengths of youth, the plasticity of human development, and the concept of resilience coalesced in the 1990s to foster the development of the concept of positive youth development (PYD) (J.V. Lerner, Phelps, Forman, \& Bowers, 2009). As discussed by Hamilton (1999), the concept of PYD was understood in at least three interrelated but nevertheless different ways:

1. as a developmental process

2. as a philosophy or approach to youth programming

3. as instances of youth programs and organizations focused on fostering the healthy or positive development of youth.

In the decade following Hamilton's (1999) discussion of PYD, several different models of the developmental process believed to be involved in PYD were used to frame descriptive or explanatory research across the adolescent period (e.g., Benson, Scales, \& Syversten, 2011; Damon, 2004; Larson, 2000; Lerner et al., 2005). As we argue below, all of these models of the 
developmental process reflect ideas associated with what are termed "relational developmental systems" conceptions of human development (e.g., Overton, 2010). However, it is unclear what particular model of developmental process is explicitly used in either "philosophical" approaches to youth programming pertinent to PYD or in particular instances of youth programs designed to foster PYD. This lack of integration represents one of several important obstacles to a fully reciprocal relation between practice and theory-predicated research in the service of the promotion of PYD.

A key goal of this article is to identify and propose means to address what we regard as "problematics" in the application of developmental science in the service of describing, explaining, and optimizing the course of development among diverse youth. To address this goal we will use the tripartite conception of PYD suggested by Hamilton (1999) as a frame to review briefly key instances of:

1. the different theoretical models of the PYD developmental process

2. philosophical ideas about, or conceptual approaches, to the nature of youth programming

3. key instances of programs aimed at promoting PYD.

We will conclude our discussion by pointing to a means to generate integrative, theoreticallypredicated, evidence-based actions that would be appropriate to take by practitioners in youth programs, by youth-serving organizations, and by policy makers.

\section{PYD as a Developmental Process}

Developmental science seeks to describe, explain, and optimize intraindividual change and interindividual differences in intraindividual change across the life span (Baltes, Reese, \& Nesselroade, 1977). The contemporary, cutting-edge theoretical frame for such scholarship involves relational developmental systems theoretical models (Overton, 2010). These models emphasize that the basic process of human development involves mutually influential relations between the developing individual and the multiple levels of his/her changing context. These bidirectional relations may be represented as individual $\leftarrow \rightarrow$ context relations. These relations regulate (govern) the course of development (its pace, direction, and outcomes). When these "developmental regulations" involve individual $\leftrightarrow \rightarrow$ context relations benefitting both the person and his or her ecology, they may be termed "adaptive" (Brandtstädter, 2006).

Examples of these models include Bronfenbrenner's bioecological theory (e.g., Bronfenbrenner \& Morris, 2006), action theory models of intentional, goal-directed behaviors (e.g., Baltes, 1997; Brandtstädter, 2006; Heckhausen, 1999), Elder's (1998) life-course theory, the Thelen and Smith (2006) approach to dynamic systems theory, Magnusson's (1999; Magnusson \& Stattin, 2006) holistic person-context interaction theory, and the Ford and Lerner (1992) and Gottlieb (1998) developmental systems formulations.

History, or temporality, is part of the ecology of human development that is integrated with the individual through developmental regulations. As such, there is always change and, as well, at least some potential for systematic change (i.e., for plasticity), across the life span (Lerner, 2002). This potential for change represents a fundamental strength of human development. Of course, plasticity means that change for the better or worse can characterize any individual's developmental trajectory. Nevertheless, a key assumption of relational developmental systems theories is that the developmental system is sufficiently diverse and complex for some means to 
be found (by researchers, practitioners, or individuals themselves) to couple individual and context in manners that enhance the probability of change for the better, of promoting more positive features of human development (J.V. Lerner et al., 2009). Given the enormity of the individual and contextual changes characterizing the adolescent period, and the fact that, in adolescence, the individual has the cognitive, behavioral, and social relational skills to contribute actively and often quite effectively to his or her own developmental changes (Lerner \& Walls, 1999), adolescence is an ideal "ontogenetic laboratory" for studying the plasticity of human development and for exploring how coupling individual and contexts within the developmental system may promote positive development during this period.

\section{The Study of Adolescence within the Developmental System}

Multiple dimensions of profound changes are prototypic of the adolescent period, involving levels of organization ranging from the physical and physiological, through the cognitive, emotional, and behavioral, and to the social relational and institutional. If adaptive developmental regulations emerge or can be fostered between the plastic, developing young person and features of his context (e.g., the structure and function of his/her family, school, peer group, and community), then the likelihood will be increased that youth may thrive (that is, manifest healthy, positive developmental changes) across the adolescent decade.

Predicated on relational developmental systems theory, the links among the ideas of plasticity, adaptive developmental regulations, and thriving suggest that all young people have strengths that may be capitalized on to promote more positive development across the adolescent years. For instance, one example of the emerging strengths of adolescents is their ability to contribute intentionally to the adaptive developmental regulations with their context (Gestsdóttir \& Lerner, 2008). Such intentional self regulation may involve the selection of positive goals (e.g., choosing goals that reflect important life purposes), using cognitive and behavioral skills (such as executive functioning or resource recruitment) to optimize the chances of actualizing one's purposes and, when goals are blocked or when initial attempts at optimization fail, possessing the capacity to compensate effectively (Freund \& Baltes, 2002).

The convergence of the ideas of plasticity, adaptive developmental regulations, and thriving enable the assertion that all young people constitute "resources to be developed" (Roth \& Brooks-Gunn, 2003). Increasingly, this strength-based view of adolescents has been used to study youth development within the United States (e.g., J.V. Lerner et al., 2009) and internationally (e.g., Gestsdóttir \& Lerner, 2007; Silbereisen \& Lerner, 2007). Moreover, this research has been framed by the ideas of individual $\leftrightarrow \rightarrow$ context relations within relational developmental systems models, and constitute the views of the PYD developmental process. Hamilton (1999) pointed to these conceptions of the PYD developmental process as indicating the first way in which the concept of PYD was approached within the field of youth development.

\section{Approaches to PYD as a Developmental Process}

Current theoretical conceptions of the PYD developmental process have been framed within the relational developmental systems meta-theoretical perspective (e.g., see Damon, 2004; Larson, 2000, J. Lerner et al., 2009). Nevertheless, there are several different instantiations of this theoretical approach.

William Damon and the Study of Purpose.

William Damon (2008; Mariano \& Damon, 2008) approaches the study of the PYD process through an examination of the development of purpose in youth. Damon notes that a central 
indicator of PYD and youth thriving (i.e. exemplary positive development; Lerner, 2004; Benson et al., 2011) is engagement in pursuits that serve the common welfare, and makes meaningful contributions to communities. Damon assesses the ways in which youth go beyond their own self-centered needs and extend outward to the pursuit of goals that benefit the world beyond.

To Damon (2008), a purpose is a stable and generalized intention to accomplish something that is at once meaningful to the self and is of intended consequence to the world beyond the self. It is an "ultimate concern" or overall goal for one's life, helping to organize one's life decisions and actions, and is thus manifested in one's behavior. The purpose is internalized, or "owned" by the individual, and therefore is central to his or her identity. As such, the operational criteria of purpose are:

- the person must have all elements of the definition: something to accomplish, a beyond-the-self rationale, plans for future action, meaningfulness to self, and incorporation into one's identity (that is, behavior that is not driven by oughts);

- the concern must function to organize the person's decisions and activities in support of the concern;

- $\quad$ the person must manifest the concern with visible action; and

- the person cannot imagine himself/herself without the concern, it is necessary to do the activities related to the concern.

While Damon (2008) sees purpose as an indicator of PYD, he notes that a next step in his research will require a deeper understanding of the ways that young people are purposeful. Purposeful young people may indeed be contributing to something beyond themselves, but whether that contribution is for self-serving reasons and social approval, or an end in itself, may be an important distinction for understanding how purpose and contribution are associated with different facets of adolescent development.

\section{Peter Benson and Search Institute and the Study of Developmental Assets.}

The work of Peter Benson and his colleagues at Search Institute (e.g., Benson, 2008; Benson, Scales, \& Syvertsen, 2011) have been integral in providing the vocabulary and vision about the strengths of young people and the communities in which they reside. Coining the term "developmental assets," Benson and his colleagues describe "internal" or individual assets, which are a set of "skills, competencies, and values" of a young person, grouped by four categories (Benson et al., 2011):

1. commitment to learning

2. positive values

3. social competencies

4. positive identity.

These individual assets represent the talents, energies, strengths, constructive interests, and "sparks" that every young person possesses (Benson, 2008). Thriving occurs as a result of aligning these individual strengths with a community's "external" or ecological assets, which are conceived as "environmental, contextual, and relational features of socializing systems" and are organized into four categories (e.g., Benson et al., 2011):

1. support

2. empowerment 
3. boundaries and expectations

4. constructive use of time.

These developmental assets have been conceptualized in a way to emphasize and encourage their practical application by highlighting the role of communities in fostering well-being and positive development among young people. Current work by Benson and colleagues (e.g., Benson et al., 2011) seeks to extend the applicability of the approach to diverse youth, both in the U.S. and internationally.

Jacquelynne Eccles and the Study of Stage-Environment Fit and Motivation. Jacquelynne Eccles' work focuses on elucidating how a "fit" between contextual variables (e.g., schools, families, and youth programs) and individual characteristics (e.g., expectations, values) contributes to the healthy, positive development of adolescents (e.g., Eccles \& Wigfield, 2002). Through a focus on assessing early and middle adolescents' transitions to junior high or middle school and participation in youth programs, Eccles and colleagues have forwarded a theoretically rich and empirically robust body of work indicating that schools and youth programs must be developmentally appropriate for the youth populations they serve in order to ensure a "stage-environment fit" that motivates adolescents and promotes their positive youth development (e.g., Eccles, 2004).

Much of Eccles' work examines the roles of motivational beliefs, values, and goals on an adolescent's positive development. In order to study these factors, Eccles and colleagues tested an expectancy-value model of achievement-related choices (e.g., Eccles, 2004). This model holds that an individual's activity choice, persistence, and performance are related to his or her expectations of success and value for the activity which, in turn, are also influenced by a variety of other personal and contextual factors (Eccles \& Wigfield, 2002).

Using this model, Eccles and colleagues have identified the various characteristics of schools that better support an adolescent's expectancy for success and value for academic goals (Eccles \& Roeser, 2009). For example, these school characteristics include teacher's expectations for high student achievement and the provision of structured after-school activities (e.g., Eccles \& Gootman, 2002). Eccles and colleagues have also found that several characteristics common to the United States education system, most notably the transition into junior high or middle school, often have adverse effects on young adolescents' motivation, achievement, and positive development (e.g., Eccles \& Roeser, 2009).

Reed Larson and the Study of Motivation, Active Engagement, and Real-Life Challenges. For Larson (2006), PYD is "a process in which young people's capacity for being motivated by challenge energizes their active engagement in development" (p. 677). For positive development to occur, the motivational system must become activated and remain engaged in multiple domains of development while young people deal with everyday real life challenges. Larson characterizes a young person's initiative as both a key component of PYD and, as well, an important focal point for youth development programs seeking to promote PYD (Larson, 2000). Defining initiative as "the capacity to direct cumulative effort over time toward achievement of a long term goal" (Larson, Hansen, \& Walker, 2005, p. 160), Larson (2000) posits that initiative is a central requirement for "components of PYD, such as creativity, leadership, altruism, and civic engagement" (p. 170).

Larson's work looks at the match between the experiences of adolescents and the requirements of the adult world they are preparing to enter. He seeks to understand this integration by 
describing the diversity of developmental tasks, skills, and competencies adolescents need to develop to transition successfully into adulthood in different cultures. With his focus on agency and initiative, much of the recent work by Larson and colleagues focuses on how youth development programs can best develop these and related skills in participating youth (e.g., Dawes \& Larson, 2011). Larson has suggested that across diverse programs, an important component for the development of initiative may be the concurrent development of personal connections with adult leaders or other participating peers.

Out-of-school-time (OST) activities are key program contexts Larson has considered in depth. OST programs with structured activities are seen as contexts in which youth can act as producers of their own positive development (Eccles \& Gootman, 2002); such programs offer opportunities to develop skills and competencies necessary for negotiating the real world (Mahoney, Vandell, Simkins, \& Zarrett, 2009). These skills and competencies include taking initiative, developing leadership, and learning responsibility, as well as strategic and teamwork skills (e.g., Larson, 2000; Larson, Walker, \& Pearce, 2005). At the same time, participation in structured OST activities may be associated with negative experiences such as stress, inappropriate adult behavior, negative influences, social exclusion, and negative group dynamics. Accordingly, Larson seeks to specify the approach that needs to be taken in community-based, OST programs in order to promote PYD.

\section{Margaret Beale Spencer and the PVEST Model.}

Margaret Beale Spencer's Phenomenological Variant of Ecological Systems Theory (PVEST) is a dynamic and systemic framework for studying development that takes into account structural factors, cultural influences, and individual experiences, as well as individuals' perceptions of these features (Spencer, 2006). A central component of this model is an emphasis on the ways in which youth make sense of their contexts, and the role that these understandings play in their perceptions of events, people, and opportunities in their environments. The work of Spencer and her colleagues has focused on how minority American youth evaluate themselves based on the stereotypes and biases of others, particularly in the context of stressful risk environments (Spencer, 2006). The PVEST model emphasizes the role of coping strategies that youth develop in different contexts, which in turn provide feedback regarding the adolescent's emerging identity and lead to positive or negative developmental outcomes.

An important theoretical idea within the PVEST model for the study of PYD is that youth from diverse backgrounds will experience the same events and settings through different lenses, which can yield different interpretations and effects. While an after-school homework club might promote academic competence for some youth, for others the same context might evoke reminders of earlier unavailability of resources, such as access to books and teacher help. The effectiveness of this asset, then, is likely to vary according to youth perceptions of this setting. Accordingly, Spencer argues that the role of structural inequality must be considered within this approach to PYD.

\section{Stephen Hamilton and Mary Agnes Hamilton and Positive Adolescent-to-Adult Transitions.}

The scholarship of Hamilton and Hamilton (e.g., Hamilton, 1994; Hamilton \& Hamilton, 2009) elucidates the developmental processes that encompass the transition from adolescence to adulthood, with a particular emphasis on the school-to-work transition and the role of adults, programs, and institutions in supporting this transition. The transition to adulthood is defined by changes in social roles, as adolescents shift from being dependent upon adults to being capable of caring for self and others. This shift is structured by the many contexts in which a youth is embedded - family, school, work, society. 
The Hamiltons' scholarship helps frame understanding of the issues faced by youth trying to connect school and work. In addition, they offer ideas for policies and programs useful for enhancing the school-to-work connection for all youth and, in particular, for those adolescents who seek full-time employment immediately after completion of high school. For instance, studying adolescents and young adults from seven nations - United States, Germany, Japan, Austria, Switzerland, Denmark, and Sweden - Hamilton (1994) noted that "Adolescents who believe their current efforts will bring them closer to a desirable future are far more likely to work hard in school and avoid self-destructive behavior than those who are either unable to think about the future or who believe their prospects are beyond their control" (pp. 267-268).

To attain the link they desire between their adolescent school context and their young adult work context, adolescents must consider two key facets of the worlds of education and work/career: transparency and permeability. Transparency involves seeing through the intricacies of the stated and the unstated rules of the educational system and the labor market, and permeability involves the amount of effort needed to move from one career plan to another.

\section{Ann Masten and the Study of Resilience.}

Masten (2001) notes that to be considered "resilient," an individual must not only be identified as experiencing adversity, but he or she must also be deemed as doing "good" or "OK" in terms of the quality of adaptation or developmental outcome. Accordingly, her work involves "understanding behavior problems in the full context of human development... focus(ing) on variations in adaptation" (Masten, 2004, p. 311). She believes that research on positive and maladaptive functioning and development are mutually informative (Masten, 2001, 2004).

Masten's work on determining what constitutes positive adaptation focuses on competence in age-salient developmental tasks (e.g., Masten, 2001; Masten, Obradović, \& Burt, 2006). Thus, resilience is a dynamic construct, as developmentally appropriate tasks vary according to the age of the individual as well as to the cultural and historical context in which the individual was raised. Competence in managing the salient developmental tasks of one's sociocultural context is also a multidimensional assessment of adaptation, as there are multiple tasks during any given developmental stage in any given place at any given time. Within this framework, maladaptive development would be operationalized as failure to meet the expectations of a given society for several domains of development or for one major domain (Masten, 2001).

According to Masten (2001), resilience occurs as the result of mutually-influential individual $\leftarrow \rightarrow$ context relations. Therefore, young people whose lives are characterized as resilient may be identified not only by the competence they develop with respect to developmental tasks, but also by the quality of resources available to them. This conceptual orientation has led Masten to study the cascades of individual $\leftarrow \rightarrow$ context relations that are linked to the presence of resilience in adolescent development, arguing that different interactions occur in developing systems and result in spreading effects across levels, among domains at the same level, and across different systems or generations, that is, the different interactions have cumulative consequences for development (e.g., Masten \& Cicchetti, 2010).

\section{Richard M. Lerner, Jacqueline V. Lerner, and Colleagues and the Study of Individual $\leftrightarrow \rightarrow$} Context Relational Processes and PYD.

Lerner, Lerner, and colleagues have conducted longitudinal research that seeks to identify the individual and ecological relations that may promote thriving and that, as well, may be linked to 
lower levels of risk/problem behaviors. This research is exemplified by the 4-H Study of Positive Youth Development (e.g., R.M. Lerner et al., 2005), in which thriving is conceptualized as the growth of the "Five Cs" of PYD - Competence, Confidence, Character, Connection, and Caring (Eccles \& Gootman, 2002; R.M. Lerner et al., 2005; Roth \& Brooks-Gunn, 2003).

A key hypothesis tested is that if (a) the strengths of youth - for example, a young person's cognitive, emotional, and behavioral engagement with the school context, having the "virtue" of hope for the future, or possession of the intentional self-regulation skills of Selection [S], Optimization [O], and Compensation [C] - can be aligned with (b) the resources for positive growth found in families, schools, and communities, for instance, the capacities of adults to provide for young people a nurturing, positive milieu in which their strengths may be enhanced and positively directed (e.g., Rhodes \& Lowe, 2009), then (c) young people's healthy development may be optimized (R.M. Lerner, 2004). In addition, given that positively developing youth should be involved in adaptive developmental regulations, then a thriving young person should act to contribute to the context that is benefiting him or her; youth should contribute to self, family, community, and civil society (Bowers et al., 2010; Jeličič, Bobek, Phelps, Lerner, \& Lerner, 2007; R.M. Lerner et al, 2005).

In other words, if positive development rests on mutually-beneficial relations between the adolescent and the assets of his/her ecology, then thriving youth should be positively engaged with and act to enhance their world. As well, they should be less prone to engage in risk/problem behaviors. Figure 1 presents an illustration of this conception of the PYD developmental process. 
Figure 1

A relational developmental systems model of the individual $\leftarrow \rightarrow$ context relations involved in the Lerner and Lerner conception of the PYD developmental process.

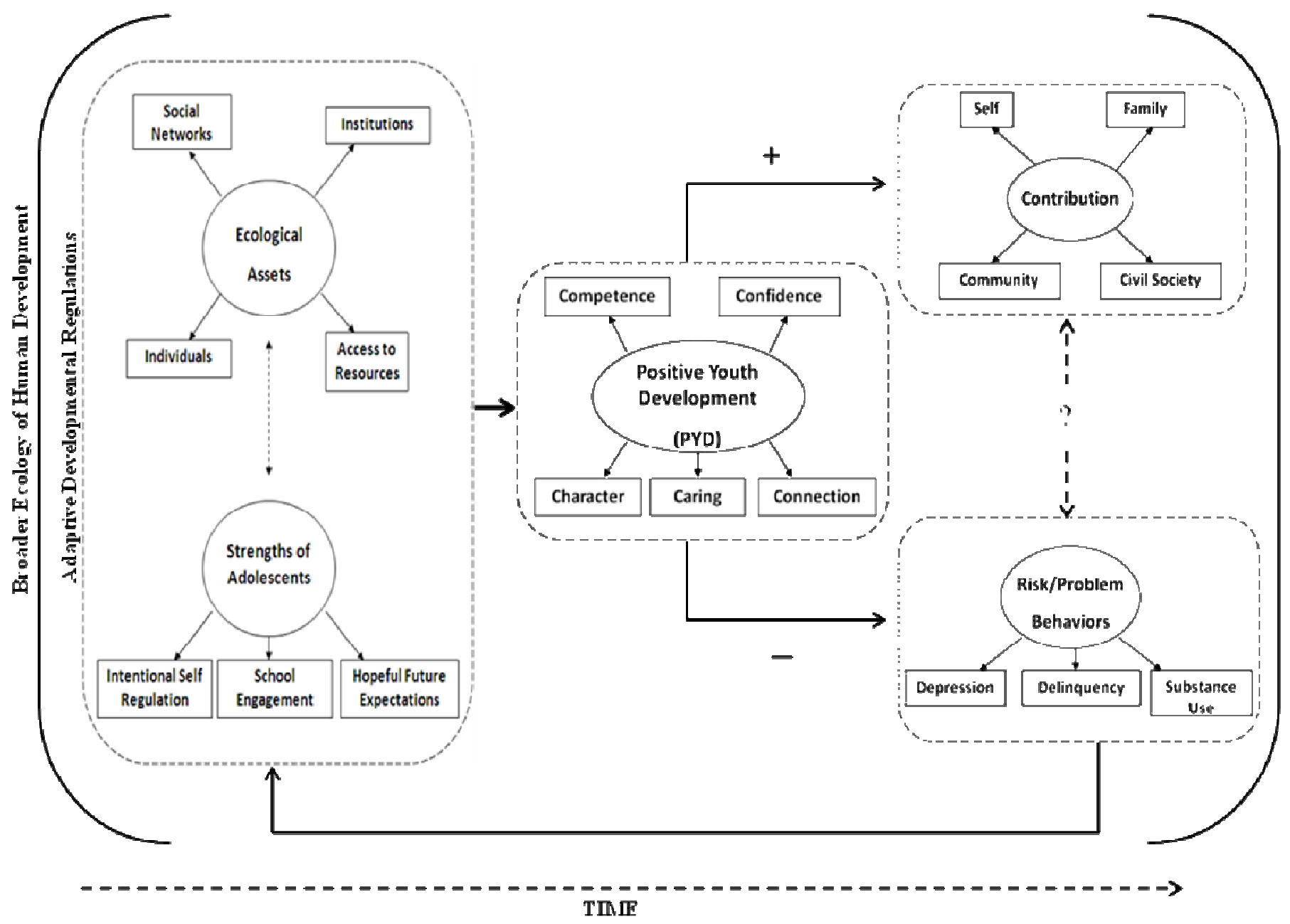

\section{Conclusions}

As we turn now to a discussion of PYD as a philosophy or approach to understanding, or conceptualizing, youth programs, we may note that many contributors to this literature indicate an awareness of the theoretical literature about developmental processes. However, we may note also that there is little explicit linkage between intraindividual changes included in these processes and specific components of the philosophy or approach.

\section{PYD as a Philosophy or Approach to Youth Programming}

The second component of Hamilton's (1999) definition of PYD is that it is a philosophy or approach to youth programming. There are numerous excellent examples of this second facet of PYD, the most prominent and influential one being the Eccles and Gootman (2002) National Academy of Sciences report on community programs to promote youth development. The report discusses the design, implementation, and evaluation of community programs for youth and conceptualizes PYD in regard to the skills, knowledge, and other personal and social assets 
required to move successfully from healthy adolescence into competent adulthood. Eccles and Gootman (2002) based their report on the work of scholars who contributed to the National Academy of Sciences' Committee on Community-Level Programs for Youth. These scholars defined four domains of individual assets that represent health and well-being in adolescence:

1. physical development

2. intellectual development

3. psychological and emotional development

4. social development.

They noted that positive development does not require possession of all assets. Having more assets, however, is better than having fewer and it is beneficial to have assets in all four domains. Eccles and Gootman (2002) indicated that that these assets do not exist in a vacuum and do not in themselves ensure the well-being of adolescents. Youth need access to contexts that facilitate their development through exposure to positive experiences, settings, and people, and to contexts that provide opportunities to develop and refine real-life skills. It is important for every community to have an array of programs for youth that, taken together, offer all features of positive developmental settings.

Some of the features that characterize such positive developmental settings include physical and psychological safety, appropriate structure, and positive social norms. These contexts provide opportunities to enjoy supportive relationships, to belong, to build skills and to feel empowered by experiencing efficacy and a sense of mattering. Moreover, these settings need to be synergistic with efforts and perspectives of the adolescents' families, as well as with the communities in which both the programs and the adolescents reside. While acknowledging the list as provisional, Eccles and Gootman (2002) suggested that youth-serving professionals take these factors into consideration when planning, designing, and evaluating programs for the youth with whom they work.

Many other philosophies/approaches to youth programs exist (e.g., see Dryfoos, 1990; Dukakis, London, McLaughlin, \& Williamson, 2009; Heck \& Subramaniam, 2009). For instance, Catalano, Hawkins, Berglund, Pollard, and Arthur (2002) and Catalano, Berglund, Ryan, Lonczak, and Hawkins $(1999,2004)$ identified several characteristics that mark effective youth development programs, for instance, a structured curriculum and measured reductions in problem behaviors, increases in positive behavior, or most optimally, both types of outcomes. In addition, effective programs were delivered over a period of at least nine months and were implemented with quality, consistency, and fidelity to the standards established by the program's model. Moreover, Catalano et al. $(1999,2004)$ specified the set of positive outcomes that effective youth programs fostered. Specifically, they noted that programs were effective when they promoted at least five of fifteen outcomes in youth, including:

- bonding

- resilience

- social competence

- emotional competence

- cognitive competence

- behavioral competence

- moral competence

- self-determination 
- $\quad$ spirituality

- self-efficacy

- clear and positive identity

- belief in the future

- recognition for positive behavior

- opportunities for prosocial involvement

- prosocial norms.

In turn, Roth and Brooks-Gunn (2003) investigated community-based programs to understand what exactly is meant by the term "youth development program." They identified three critical characteristics of such programs:

1. specific program activities

2. atmosphere

3. goals.

Moreover, they noted that the goals of youth development programs go beyond prevention to include the promotion of positive development. They are characterized by an atmosphere of hope, caring, safety, cultural appropriateness and respect of adolescents' abilities to make choices and bear responsibility. Program activities provide opportunities for active involvement and meeting new challenges.

Similarly, Blum (2003) identified four elements critical to successful youth interventions: People, Contributions, Activities, and Place. Successful interventions are those that build strong adultyouth relationships (People), include active involvement of youth in giving back to family, school, and community (Contributions), offer productive and recreational opportunities for youth (Activities), and provide a safe environment free from drugs and violence with adult supervision (Place).

Building on the work of both Roth and Brooks-Gunn (2003) and Blum (2003), as well as others (e.g., Rhodes, 2002), R. M. Lerner (2004) argued that there are three fundamental characteristics of effective PYD programs. These "Big Three" characteristics are:

1. Positive and sustained adult-youth relations, relations (relations between a young person and an adult who is competent, caring, and continually available, for at least a year, such as a mentor, coach, or teacher)

2. Life-skill building activities (e.g., enhancing skills pertinent to the selection, optimization, and compensation skills we discussed earlier; Gestsdóttir \& Lerner, 2008)

3. Opportunities for youth participation in and leadership of valued family, school, and community activities.

Lerner argued as well that these features of youth programs needed to be simultaneously and integratively present for PYD to be effectively promoted.

In addition, Heck and Subramaniam (2009) described five other youth development program philosophies/approaches or, in their terms, development frameworks, which they defined as a 
conceptualization that "helps give direction and purpose to a program" (p. 2). The five frameworks they discuss are:

1. Targeting Life Skills

2. Developmental Assets (as conceptualized by Search Institute; e.g., Benson, Scales, Hamilton, and Sesma, 2006)

3. The Four Essential Elements

4. The Five Cs

5. The Community Action Framework for Youth Development.

In their review, Heck and Subramaniam (2009) compared the strengths and limitations of the five models in terms of their effectiveness, which is evaluated by the criteria of validity (scientific evidence), utility (extent of use and availability of instruments), and universality (applicability to various populations).

The Targeting Life Skills model details the life skills encapsulated by 4-H's Heart, Hands, Head, and Health (Hendricks, 1996); this model is meant to serve as a plan for youth programming. Each of the four components is composed of two general categories of skills, with the two categories composed of more specific life skills. For example, "Hands" is divided into working and giving; giving is further divided into community service, leadership, responsible citizenship, and contributions to group effort; working is further divided into marketable skills, teamwork, and self motivation. The model helps to identify specific skills that a youth-based program should focus on, rather than being a theoretical model of development (Heck \& Subramaniam, 2009).

The Developmental Assets model as conceptualized by the Search Institute (Benson et al., 2011) identifies resources available to young people that promote positive development. Benson and colleagues have generated a list of 40 developmental assets, both internal and external to young people, that have been linked to positive youth outcomes. We noted earlier the internal and external asset categories studied by Benson et al. (2011). As indicated as well in the approach forwarded by Eccles and Gootman (2002), higher levels of assets have been related to positive developmental outcomes, such as higher school achievement, better physical health, lower levels of risk behaviors, and resilience (e.g., Benson et al., 2011). Heck and Subramanian (2009) reported that research (and evaluation) about the application of the Developmental Assets model to youth programs is sparse.

The Four Essential Elements of Youth Development are identified as belonging, mastery, generosity, and independence and were originally proposed as the "Circle of Courage" (Brendtro, Brokenleg, \& Van Bockern, 1990). These four elements were further subdivided into eight elements that were identified as critical to developing positive youth outcomes in youth development programming (Peterson et al., 2001). Belonging includes having relationships with caring adults, an inclusive environment, and a safe environment; mastery includes opportunities for mastery and engagement in learning; generosity consists of the opportunity to value and practice service for others; and independence includes opportunities to see oneself as an active participant in the future and the opportunity for self-determination.

The Community Action Framework for Youth Development (Gambone, Klem, \& Connell, 2002; Gambone \& Connell, 2004) includes five hierarchical organized strategies for use by both practitioners and scientists. These five strategies are building community capacity and conditions for change; implementing community strategies to enhance supports and 
opportunities for youth; increasing supports and opportunities for youth; improving youth development outcomes; and improving long-term outcomes in adulthood. To implement these strategies programs must meet five key requirements: adequate nutrition, health and shelter; multiple supportive relationships; challenging and engaging activities and experiences; meaningful opportunities for involvement; and physical and emotional safety. The Community Action Framework for Youth Development is intended to create communities in which all young people can optimize their potential. The Framework is meant to be a systematic approach to planning, implementing, and evaluating programs and resources for youth. In this regard, the Framework does enumerate supports and opportunities that overlap with the elements of effective youth programs presented in other approaches.

In turn, as noted earlier in the discussion of the Lerner, Lerner, and colleagues' relational developmental systems model of the PYD process (e.g., R.M. Lerner, et al., 2005), the Five Cs model of youth development conceptualizes PYD as composed of Five Cs - Competence, Confidence, Connection, Character and Caring. The Cs are a means to operationalize the developmental characteristics that a youth needs to become a successful and contributing member of society. These Five Cs were linked to the positive outcomes of youth development programs reported by Roth and Brooks-Gunn (2003). In addition, these "Cs" are prominent terms used by practitioners, adolescents involved in youth development programs, and the parents of these adolescents in describing the characteristics of a "thriving youth" (King et al., 2005).

Heck and Subramaniam (2009) indicate that each of the above-noted five approaches has varying levels of empirical support. However, none of the frameworks have been linked to research that provides evidence of universal applicability, although from a relational developmental systems perspective, such universality is not even possible, given that the world is seen as variegated and changing (R.M. Lerner, 2002; Overton, 2010). They indicated, however, that the Five Cs Model of PYD is the most empirically supported framework to date. Empirical evidence indicates that this construct has good psychometric properties (e.g., Bowers et al., 2010).

While the Five Cs model may be an empirically useful means to study the PYD process, it is not clear from the conceptualization of the Five Cs model how to translate it into a specific youth development program. Work on such translation is beginning, however, in regard to coaching youth sports programs (e.g., Haskins, 2010) and to mentoring programs for youth (Napolitano, Bowers, Gestsdóttir, \& Chase, 2011).

In addition, Heck, Subramaniam, and Carlos (2010) discuss a sixth framework, the Step-It-Up2-Thrive Theory of Change that was formulated by the Thrive Foundation for Youth. The Thrive Foundation developed this model in collaboration with several developmental scientists and has produced material for use in mentoring programs. The goal of this theory of change is to put youth on thriving trajectories. The theory is composed of several research-based components that build upon each other and follow a logical sequence in order to improve the likelihood that a youth will thrive:

1. Identify and develop "sparks" (Benson, 2008);

2. Adopt a growth mindset (Dweck, 2006);

3. Reflect on twelve indicators of thriving (that can be organized within the Five Cs of PYD and the "Sixth C" of youth contribution; Jeličić, et al., 2007; R. M. Lerner et al., 
2005), and identify indicators to focus on as part of the mentoring relationship (King et al., 2005; R.M. Lerner et al., 2005); and

4. Build goal management skills through goal selection, pursuit of strategies, and shifting approaches in the face of challenges (e.g., Gestsdóttir \& Lerner, 2007, 2008).

The Step-It-Up-2-Thrive model emphasizes also the importance of positive and caring relationships between an adult and youth, foci that are emphasized in other PYD approaches to youth programming (such as "The Big Three" described earlier).

Finally, Dukakis et al. (2009) argue that, in order to understand how to support the positive development of youth, practitioners need to focus on more than indicators of individual outcomes. They argue that a tri-level perspective that considers the context of youth development "is critical to identifying implementation issues associated with policies and practices intended to facilitate youth development and to addressing shortfalls and sharing successes" (p. 2). They present a model that specifies:

1. Individual-level indicators, that is, indicators of the progress of a young person along a PYD path and the outcomes of PYD;

2. Setting-level indicators, that is, indicators of the resources associated with or the opportunities provided by a youth program; and

3. System-level indicators, meaning indicators of the policy context pertinent to youth and of the youth development infrastructure present in a neighborhood, community, state, or nation.

\section{Conclusions}

The philosophies/approaches we have briefly summarized provide both researchers and practitioners with potentially useful ways to think about the characteristics and qualities of effective youth development programs. The suitability of the selection of any particular philosophy/approach by program planners will likely be based on the features that seem particularly relevant to the program they lead (Heck \& Subramaniam, 2009). In addition, this selection should be derived from the practitioner's use of a particular theory of change that is embedded within a specific model of the PYD process.

We have noted that it is often not clear that specific theoretical models of the PYD process have been used to shape the philosophies/approaches to PYD programs. In addition, it is ironically the case that, when such a connection seems evident (e.g., as appears to be the case with both the Developmental Assets framework and the Five Cs model; Heck \& Subramaniam, 2009), it is unclear how these theories of process provide a specific approach to (i.e., a particular logic model for) to youth programs. As we have noted, work on this translation is only in its nascent period (Haskins, 2010; Napolitano et al., 2011), despite some correspondence between elements of the theoretical models and some features or targeted outcomes of the philosophy/approach to youth programming, for example, involving a focus on both the individual and the context (for instance, on the significance of positive adult-youth relationships). In turn, there exists also a need for more clarity about connections between philosophies/approaches to youth programs and particular instances of programs aimed at promoting PYD. 


\section{PYD as Instances of Youth Programs' and Organizations' Focus}

In the U. S. there are literally thousands of instances of community-based programs that seek to promote PYD (e.g., Dryfoos, 1990; Roth \& Brooks-Gunn, 2003; Mahoney, et al., 2009) or its theoretically-related outcomes, for example, active engaged citizenship (Zaff, KawashimaGinsberg, \& Lin, 2011); as well, there are numerous national organizations that seek to provide such programs throughout the U.S., including 4-H, Boys \& Girls Clubs, Big Brothers/Big Sisters, Boy Scouts, Girl Scouts, YMCA, and Girls Inc. (e.g., Zaff, et al., 2011). Discussing these programs or organizations in detail is obviously beyond the scope of this article. Our purpose here is to illustrate the third instance of Hamilton's (1999) tripartite definition of PYD and point to the current nature of the connections between this facet of PYD and the other two facets we have discussed.

There are many instances of programs that are effective in promoting PYD, operationalized for instance in regard to the links between program characteristics and the development or enhancement of one or more of the Five Cs (e.g., see Roth \& Brooks-Gunn, 2003). Accordingly, we will use one exemplary PYD program as a sample case of the sorts of programs to which Hamilton (1999) pointed. We may capitalize here on the scholarship of Flay and colleagues (Flay, 2002; Flay \& Allred, 2003), who have pointed to a comprehensive youth program, one that focuses on promoting healthy, positive development of children and youth in many domains, including academics, problem behaviors, and family relationships, as such an exemplary PYD program. Flay (2002) argued that PYD requires comprehensive health promotion programs. He explained that "to prevent problem behaviors and promote positive behaviors [we need] comprehensive, coherent, and integrated approaches" to youth programs (p. 407).

Flay and Allred (2003) illustrate such a program by describing the long-term effects of the "Positive Action" program. Features of this school-based program include interventions with the individual child or adolescent, the school, and the family. At all levels, the interventions within the program focus on the same broad concept (feeling good about oneself when taking positive actions). The specific content includes six units:

\section{1. self-concept}

2. positive actions for body and mind

3. social/emotional positive actions for managing yourself responsibly

4. social/emotional positive actions for getting along with others

5. social/emotional positive actions for being honest with yourself and others

6. social/emotional positive actions for improving continually.

A 2006 review by the National Registry of Evidence-based Programs and Practices (NREPP) notes that the Positive Action program is indeed an integrated and comprehensive program, due to evidence that it is effective in improving academic achievement and school attendance and, in turn, in diminishing problem behaviors such as substance use, violence, suspensions, disruptive behaviors, dropping out, and sexual behavior. Of course, evaluations of the effectiveness of comprehensive PYD programs like this are limited (cf. Catalano, et al., 1999). Indeed, most youth development programs in the U.S. are not evaluated (e.g., see Roth, Brooks-Gunn, Murray, \& Foster, 1998). However, the evaluation data pertinent to the Positive Action program, such as that provided by Beets et al. (2009), indicates that students who participated in the program were less likely to engage in substance use, violence, and sexual activity than students who did not participate in the intervention, based on student self-report 
and teachers' reports. This evaluation, however, has limitations in terms of sample; it includes only young adolescents (fifth grade students) in a specific geographical and cultural setting (Hawaii).

Nevertheless, despite such limitations of a particular evaluation research study, the Positive Action program has demonstrated effectiveness and is an excellent example of the third facet of the definition of PYD discussed by Hamilton (1999). Moreover, in including in its design a comprehensive, individual and contextual approach to intervention, the Positive Action program reflects key ideas found within instances of the other two facets of Hamilton's (1999) tripartite definition of PYD.

\section{Conclusions}

As was the case with the links between theoretical models of the PYD process and philosophies/approaches to PYD programs, there are consistencies between what actions occur within actual, exemplary PYD programs and these two other facets of the Hamilton (1999) tripartite conception of PYD. However, these connections are often not drawn explicitly by practitioners enacting PYD programs.

Indeed, across the work associated with these three facets of Hamilton's (1999) definition, these domains of the PYD field exist as Venn diagrams whose degrees of overlap remain uncertain. We believe this lack of specification, and the incomplete integration of the domains of basic and applied scholarship pertinent to PYD that it reflects, constitutes a challenge to best advancing knowledge of how to understand and promote thriving among diverse youth. There are several problematics involved in increasing the integration among the three domains of scholarship pertinent to PYD.

\section{Problematics of Integrating the Three Domains of PYD Scholarship}

The lack of integration within and across each domain of PYD scholarship provides uncertainties in regard to understanding how to optimize PYD. In regard to the theoretical models of the PYD process, there is a lack of integration of both the structural and measurement models framing empirical tests of the models. For instance, the measurement of ecological development assets differs between the research of Lerner and Lerner and their colleagues (e.g., see Theokas \& Lerner, 2006; Urban, Lewin-Bizan, \& Lerner, 2010) and the research of Benson and colleagues at Search Institute (e.g., Benson et al., 2011). Similarly, variation exists in regard to the conceptualization and measurement of the motivational, purposive, or goal-oriented behaviors of interest to Damon (2008), Eccles (e.g., Eccles \& Roeser, 2009; Eccles \& Wigfield, 2002), Larson (2000), and Gestsdóttir and Lerner (2007, 2008). Even more abstractly, there is little information about whether, across theoretical models, there exist similar views about the actions that are integrated within individual $\leftarrow \rightarrow$ context relations of interest in all theories.

Given such variation, there is no certainty that similar empirical referents exist in regard to information about the PYD process. Such uncertainty makes it problematic to achieve any consensus about what variables, from what levels of organization within the developmental system, must be integrated in what specific ways, at what points in adolescence, to optimize what specific outcomes. Clearly, in the face of this uncertainty, what is needed is crosslaboratory integration of measurement models, perhaps through the use of a multitraitmultimethod matrix method (Campbell \& Fiske, 1959). However, the practical challenge of 
gaining the funds for such field-integration research it itself a major problematic constraining the advancement of knowledge about PYD.

Similar problematics can be raised in regard to integrating the different philosophies of or approaches to PYD programming. What are the fundamental defining characteristics of an effective PYD program? Do scholars use different terms for the same latent construct? For instance, when Roth and Brooks-Gunn (2003) think of program characteristics they believe to instantiate PYD-promoting activities, atmosphere, and goals are they pointing to the same actions as those envisioned by Blum (2003) when he discusses people, contributions, activities, and place or by R.M. Lerner (2004) when he discusses positive and sustained adult-youth relations, life skill-building activities, and opportunities for participation in and leadership of valued activities? The answer is not certain. Accordingly, it may be that there should be a "conceptual meta-analysis," perhaps undertaken in the context of a working group of scholars and practitioners involved in a thorough review of the theoretical and empirical bases from which their philosophies/approaches were derived. Again, however, issues of funding make such an undertaking problematic.

Moreover, a similar lack of integration exists in regard to the numerous instances of PYD programs. Are actions labeled in the same way actually implemented identically? In different instantiations of the "same" program, is there high fidelity of implementation? Here, answers are particularly difficult to attain because, again, most youth programs in the U.S. are not evaluated and, as well, key elements of any effective program - most critically, a theory of change and a logic model - are absent from most programs (e.g., see Roth, et al., 1998). Such errors of omission preclude scientifically rigorous evaluation and, make empirical comparisons across different programs or among different instantiations of the same program highly problematic if not impossible.

\section{Conclusions}

The fundamental problematic we face is one that is, unfortunately, traditional within the youth development field. This is the challenge of systematic integration of theory, research, and application, of creating a means through which we can overcome the conceptual, professional, and economic obstacles to coalescing theory, understanding of best practice, and the expertise of practitioners committed to enhancing the thriving of the youth with whom they work. Without such integration we cannot know what specific features (structures or functions/actions), of what specific PYD programs, for what specific youth, of what specific ages (or races, ethnicities, religions, sexes, ability statuses, immigrant status, areas of residence, regions, etc.), from what specific families, and from what specific communities, result in what specific immediate and what specific long-term outcomes. We cannot answer completely this admittedly complex question, but this question - brought to the fore by relational developmental systems theory - is precisely the question we need to answer to promote PYD among the diverse young people of our nation and world.

It has been a little more than ten years since Hamilton initially formulated the three components of PYD. Perhaps it is too much to expect in such a young area of scholarship to have the level of integration to which we are pointing. Nevertheless, we believe that as all members of the PYD scholarly community - both researchers and practitioners - come together in the service of making such integration a high-priority agenda item, funders of PYD scholarship and application will take actions to support such integrated work. Accordingly, we are hopeful that in the next 10 years we will see enhanced integration and more knowledge of 
the complex multilevel questions pertinent to promoting PYD. We look forward to a fully mature field of PYD that integrates research and practice.

Acknowledgements: The preparation of this article was supported in part by grants from the National 4-H Council and the Thrive Foundation for Youth.

\section{References}

Baltes, P.B. (1997). On the incomplete architecture of human ontogeny: Selection, optimization, and compensation as foundations of developmental theory. American Psychologist, 52, 366380.

Baltes, P.B., Reese, H.W., \& Nesselroade, J.R. (1977). Life-span developmental psychology: Introduction to research methods. Monterey, CA: Brooks/Cole.

Beets, M.W., Flay, B.R., Vuchinich, S., Snyder, F.J., Acock, A., Li, K.K., Burns, K., Washburn, I. J., \& Durlak, J. (2009). Use of a social and character development program to prevent substance use, violent behaviors, and sexual activity among elementary-school students in Hawaii. American Journal of Public Health, 99(8), 1438-1445.

Benson, P.L. (2008). Sparks: How parents can help ignite the hidden strengths of teenagers. San Francisco, CA: Jossey-Bass.

Benson, P.L., Scales, P.C., Hamilton, S.F., \& Sesma, J.A. (2006). Positive youth development: Theory, research and applications. In W. Damon (Series Ed.) \& R.M. Lerner (Vol. Ed.), Handbook of Child Psychology: Vol. 1. Theoretical models of human development (6th ed., pp. 894-941). Editors-in-Chief: W. Damon \& R.M. Lerner. Hoboken, NJ: Wiley.

Benson, P L., Scales, P.C., \& Syvertsen, A.K. (2011). The contribution of the developmental assets framework to positive youth development theory and practice. In R.M. Lerner, J.V. Lerner, \& J.B. Benson (Eds.). Advances in Child Development and Behavior. (pp. 195-228). London, England: Elsevier.

Blum, R.W. (2003). Positive youth development: A strategy for improving health. In F. Jacobs, D. Wertlieb, \& R.M. Lerner (Eds.), Handbook of applied developmental science: Vol. 2.

Promoting positive child, adolescent, and family development through research, policies, and programs (pp. 237-252). Thousand Oaks, CA: Sage.

Bowers, E.P., Li, Y., Kiely, M.K., Brittian, A., Lerner, J.V., \& Lerner, R.M. (2010). The Five Cs model of positive youth development: A longitudinal analysis of confirmatory factor structure and measurement invariance. Journal of Youth and Adolescence, 39, 720-735.

Brandtstädter, J. (2006). Action perspectives on human development. In W. Damon (Series Ed.) \& R. M. Lerner (Vol. Ed.), Handbook of Child Psychology: Vol. 1. Theoretical models of human development (6 ${ }^{\text {th }}$ ed., pp. 516-568). Hoboken, NJ: John Wiley \& Sons. 
Brendtro, L.K., Brokenleg, M., \& Van Bockern, S. (1990). Reclaiming youth at risk: Our hope for the future. Bloomington, IN: National Educational Service.

Bronfenbrenner, U. \& Morris, P.A. (2006). The bioecological model of human development. In W. Damon (Series Ed.) \& R. M. Lerner (Vol. Ed.), Handbook of Child Psychology: Vol. 1. Theoretical models of human development (6th ed., pp. 793-828). Hoboken, NJ: Wiley.

Campbell, D.T., \& Fiske, D.W. (1959). Convergent and discriminate validation by the multitraitmultimethod matrix. Psychological Bulletin, 56(2), 81-105.

Catalano, R F., Berglund, M.L., Ryan, J.A.M., Lonczak, H.S., \& Hawkins, J.D. (1999). Positive youth development in the United States: Research findings on evaluations of positive youth development programs. Seattle: University of Washington, School of Social Work, Social Development Research Group.

Catalano, R.F., Berglund, M.L., Ryan, J.A.M., Lonczak, H.S., \& Hawkins, J.D. (2004). Positive youth development in the United States: Research findings on evaluations of youth development programs. Annals of the American Academy of Political and Social Science. [Special issue] Positive Development: Realizing the Potential of Youth, 591, 98-124.

Catalano, R.P., Hawkins, J.D., Berglund, M.L., Pollard, J.A., \& Arthur, M.W. (2002). Prevention science and positive youth development: Competitive or cooperative frameworks? Journal of Adolescent Health, 31, 230-239.

Damon, W. (2004). What is positive youth development? Annals of the American Academy of Political and Social Science, 591, 13-24.

Damon, W. (2008). The path to purpose: Helping our children find their calling in life. New York, NY: Free Press, Simon \& Schuster, Inc.

Dawes, N.P. \& Larson, R. (2011). How youth get engaged: Grounded-theory research on motivational development in organized youth programs. Developmental Psychology, 47(1), 259269.

Dryfoos, J.G. (1990). Adolescents at risk: Prevalence and prevention. New York, NY: Oxford University Press.

Dukakis, K., London, R.A., McLaughlin, M., \& Williamson, D. (2009). Positive youth development: Individual, setting and system level indicators. (Issue brief: Positive youth development indicators). Stanford, CA: John W. Gardner Center for Youth and Their Communities.

Dweck, C.S. (2006). Mindset: The new psychology of success. New York, NY: Random House.

Eccles, J.S. (2004). Schools, academic motivation, and stage-environment fit. In R.M. Lerner \& L. Steinberg, Handbook of adolescent psychology (2nd ed., pp. 125-153). Hoboken, NJ: John Wiley \& Sons, Inc.

Eccles, J.S., \& Gootman, J.A. (Eds.). (2002). Community programs to promote youth development. Washington, DC: National Academy Press. 
Eccles, J.S., \& Roeser, R.W. (2009). Schools, academic motivation, and stage-environment fit. In R.M. Lerner \& L. Steinberg, Handbook of adolescent psychology: Vol. 1. Individual bases of adolescent development, ( $3^{\text {rd }}$ ed., pp. 404-434). Hoboken, NJ: John Wiley \& Sons.

Eccles, J.S., \& Wigfield, A. (2002). Motivational beliefs, values, and goals. Annual Review of Psychology, 53, 109-132.

Elder, G.H., Jr. (1998). The life course and human development. In W. Damon (Series Ed.) \& R.M. Lerner (Vol. Ed.), Handbook of child psychology: Vol. 1. Theoretical models of human development (5th ed., pp. 939-991). New York: Wiley.

Flay, B.R. (2002). Positive youth development requires comprehensive health promotion programs. American Journal of Health Behavior, 26(6), 407-424.

Flay, B.R., \& Allred, C.G. (2003). Long term effects of the Positive Action program. American Journal of Health Behavior, 2Х1), S6-S21.

Ford, D.H., \& Lerner, R.M. (1992). Developmental systems theory: An integrative approach. Newbury Park, CA: Sage.

Freund, A.M., \& Baltes, P.B. (2002). Life-management strategies of selection, optimization and compensation: Measurement by self-report and construct validity. Journal of Personality and Social Psychology, 82, 642-662.

Gambone, M.A., \& Connell, J.P. (2004). The community action framework for youth development. The Prevention Researcher, 11(2), 17-20.

Gambone, M.A., Klem, A.M., \& Connell, J.P. (2002). Finding out what matters for youth: Testing key links in a community action framework for youth development. Philadelphia, PA: Youth Development Strategies, Inc.

Gestsdóttir, S., \& Lerner, R.M. (2007). Hlutverk sjálfstjórnar í æskilegum proska barna og unglinga. Sálfræðiritid, 12, 37-55.

Gestsdóttir, S., \& Lerner, R.M. (2008). Positive development in adolescence: The development and role of intentional self-regulation. Human Development, 51, 202-224.

Gottlieb, G. (1998). Normally occurring environmental and behavioral influences on gene activity: From central dogma to probabilistic epigenesis. Psychological Review, 105, 792-802.

Hamilton, S.F. (1994). Employment prospects as motivation for school achievement: Links and gaps between school and work in seven countries. In F.K. Silbereisen \& E. Todt (Eds.), Adolescence in context: The interplay of family, school, peers, and work in adjustment. New York, NY: Springer.

Hamilton, S.F. (1999). A three-part definition of youth development. Unpublished manuscript, Cornell University College of Human Ecology, Ithaca NY. 
Hamilton, S.F., \& Hamilton, M.A. (2009). The transition to adulthood: Challenges of poverty and structural lag. In R.M. Lerner \& L. Steinberg (Eds.), Handbook of adolescent psychology: Vol. 2. Contextual influences on adolescent development, (3rd ed., pp. 492-526). Hoboken, NJ: John Wiley \& Sons, Inc.

Haskins, D. (2010). Coaching the whole child: Positive development through sports. United Kingdom: The National Coaching Foundation.

Heck, K.E., \& Subramaniam, A. (2009). Youth development frameworks. [Monograph]. Davis, CA: 4-H Center for Youth Development, University of California.

Heck, K.E., Subramaniam, A., \& Carlos, R. (2010). The Step-It-Up-2 Thrive theory of change. [Monograph]. Davis, CA: 4-H Center for Youth Development, University of California.

Heckhausen, J. (1999). Developmental regulation in adulthood: Age-normative and sociocultural constraints as adaptive challenges. New York: Cambridge University Press.

Hendricks, P.A. (1996). Targeting life skills model. Iowa State University Extension.

Jeličič, H., Bobek, D., Phelps, E., D., Lerner, J.V., Lerner, R.M. (2007). Using positive youth development to predict contribution and risk behaviors in early adolescence: Findings from the first two waves of the 4-H Study of Positive Youth Development. International Journal of Behavioral Development, 31(3), 263-273.

King, P.E., Dowling, E.M., Mueller, R.A., White, K., Schultz, W., Osborn, P., Dickerson, E., Bobek, D.L., Lerner, R.M., Benson, P.L., \& Scales, P.C. (2005). Thriving in Adolescence: The voices of youth-serving practitioners, parents, and early and late adolescents. Journal of Early Adolescence, 25(1), 94-112.

Larson, R.W. (2000). Towards a psychology of positive youth development. American Psychologist, 55, 170-183.

Larson, R.W. (2006). Positive youth development, willful adolescents, and mentoring. Journal of Community Psychology, 34, 677-686.

Larson, R.W., Hansen, D.M., \& Walker, K.C. (2005). Everybody's gotta give: Development of initiative and teamwork within a youth program. In J.L. Mahoney, R.W. Larson, \& J.S. Eccles (Eds.), Organized activities as contexts of development: Extracurricular activities, after-school and community programs (pp. 159-183). Mahwah, NJ: Lawrence Erlbaum Associates Publishers.

Larson, R.W., Walker, K.C., \& Pearce, N. (2005). A comparison of youth-driven and adult-driven youth programs: Balancing inputs from youth and adults. Journal of Community Psychology, 33(1), 57-74.

Lerner, J.V., Phelps, E., Forman, Y., \& Bowers, E.P. (2009). Positive youth development. In R.M. Lerner, \& L. Steinberg (Eds.), Handbook of Adolescent Psychology: Vol. 1. Individual bases of adolescent development (3rd ed., pp. 524-558). Hoboken, NJ: Wiley.

Lerner, R.M. (2002). Concepts and theories of human development ( ${ }^{\text {rd }}$ ed.). Mahwah, NJ: Lawrence Erlbaum Associates. 
Lerner, R.M. (2004). Liberty: Thriving and civic engagement among American youth. Thousand Oaks, CA: Sage Publications.

Lerner, R.M., Lerner, J.V., Almerigi, J., Theokas, C., Phelps, E., Gestsdóttir, S. Naudeau, S., Jeličič, H., Alberts, A.E., Ma, L., Smith, L.M., Bobek, D.L., Richman-Raphael, D., Simpson, I., Christiansen, E.D., \& von Eye, A. (2005). Positive youth development, participation in community youth development programs, and community contributions of fifth grade adolescents: Findings from the first wave of the 4-H Study of Positive Youth Development. Journal of Early Adolescence, 25(1), 17-71.

Lerner, R.M. \& Walls, T. (1999). Revisiting individuals as producers of their development: From dynamic interactionism to developmental systems. In J. Brandtstädter \& R.M. Lerner (Eds.), Action and self-development: Theory and research through the life-span (pp. 3-36). Thousand Oaks, CA: Sage.

Magnusson, D. (1999). Holistic interactionism: A perspective for research on personality development. In L.A. Pervin \& O.P. John (Eds.), Handbook of personality: Theory and research $\left(2^{\text {nd }}\right.$ ed., pp. 219-247). New York: The Guilford Press.

Magnusson, D., \& Stattin, H. (2006). The person in context: A holistic-interactionistic approach. In W. Damon (Series Ed.) \& R.M. Lerner (Vol. Ed.), Handbook of child psychology (6 ${ }^{\text {th }}$ ed., pp. 400-464). Hoboken, NJ: John Wiley \& Sons Inc.

Mahoney, J.L., Vandell, D.L., Simkins, S., \& Zarrett, N. (2009). Adolescent out-of-school activities. In R.M. Lerner \& L. Steinberg (Eds.), Handbook of Adolescent Psychology: Vol. 2. Contextual influences on adolescent development ( $3^{\text {rd }}$ ed., pp. 228-269). Hoboken, NJ: Wiley.

Mariano, J.M., \& Damon, W. (2008). The role of spirituality and religious faith in supporting purpose in adolescence. In R.M. Lerner, R.W. Roeser, \& E. Phelps (Eds.), Positive youth development and spirituality: From theory to research (pp. 210-230). West Conshohocken, PA: Templeton Foundation Press.

Masten, A.S. (2001). Ordinary magic: Resilience processes in development. American Psychologist, 56, 227-238.

Masten, A.S. (2004). Regulatory processes, risk, and resilience in adolescent development. In R.E. Dahl \& L.P. Spear (Eds.), Annals of the New York Academy of Sciences: Vol. 1021. Adolescent brain development: Vulnerabilities and opportunities (pp. 310-319). New York, NY: New York Academy of Sciences.

Masten, A.S., \& Cicchetti, D. (2010). Editorial: Developmental cascades. Development and Psychopathology, 22(3), 491-495.

Masten, A.S., Obradović, J., \& Burt, K.B. (2006). Resilience in emerging adulthood: Developmental perspectives on continuity and transformation. In J.J. Arnett \& J.L. Tanner (Eds.), Emerging adults in America: Coming of age in the $21^{\text {st }}$ century (pp. 173-190). Washington, DC: American Psychological Association.

Napolitano, C.M., Bowers, E.P., Gestsdóttir, S., \& Chase, P. (2011). The development of intentional self-regulation in adolescence: Describing, explaining, and optimizing its link to 
positive youth development. In R.M. Lerner, J.V. Lerner, \& J.B. Benson (Eds.). Advances in Child Development and Behavior. (pp. 17-36). London, England: Elsevier.

National Registry of Evidence-based Programs and Practices (2006). Review of Positive Action. Twin Falls, ID: Positive Action, Inc.

Overton, W.F. (2010). Life-span development: Concepts and issues. In R.M. Lerner (Ed-in-chief) \& W.F. Overton (Vol. Ed.), The Handbook of Life-Span Development: Vol. 1. Cognition, Biology, and Methods (pp. 1-29). Hoboken, NJ: Wiley.

Peterson, B., Gerhard, G., Hunter, K., Marek, L., Phillips, C., \& Titcomb, A. (2001). Prepared and engaged youth serving American communities: The national 4-H Impact Assessment Project. Washington, D.C.: National 4-H Headquarters.

Rhodes, J.E. (2002). Stand by me: The risks and rewards of mentoring today's youth. Cambridge, MA: Harvard University Press.

Rhodes, J.E., \& Lowe, S.R. (2009). Mentoring in adolescence. In R.M. Lerner \& L. Steinberg (Eds.), Handbook of Adolescent Psychology: Vol. 2. Contextual Influences on Adolescent Development ( $3^{\text {rd }}$ ed., pp. 152-190). Hoboken, NJ: John Wiley \& Sons Inc.

Roth, J.L., \& Brooks-Gunn, J. (2003). What exactly is a youth development program? Answers from research and practice. Applied Developmental Science, 72 ), 94-111.

Roth, J., Brooks-Gunn, J., Murray, L., \& Foster, W. (1998). Promoting healthy adolescents: Synthesis of youth development program evaluations. Journal of Research on Adolescence, $8(4), 423-459$.

Silbereisen, R.K., \& Lerner, R.M. (Eds.). (2007). Approaches to positive youth development. London: Sage Publications

Spencer, M.B. (2006). Phenomenology and ecological systems theory: Development of diverse groups. In W. Damon (Series Ed.) \& R.M. Lerner (Vol. Ed.), Handbook of child psychology: Vol. 1. Theoretical models of human development (6th ed., 829-893). Hoboken, NJ: John Wiley \& Sons.

Thelen, E., \& Smith, LB. (2006). Dynamic systems theories. In W. Damon (Series Ed.) \& R.M. Lerner (Vol. Ed.), Handbook of Child Psychology: Vol. 1. Theoretical models of human development (6th ed., pp. 258-312). Hoboken, NJ: Wiley.

Theokas, C., \& Lerner, R.M. (2006). Observed ecological assets in families, schools, and neighborhoods: Conceptualization, measurement and relations with positive and negative developmental outcomes. Applied Developmental Science, 10(2), 61-74.

Urban, J.B., Lewin-Bizan, S. \& Lerner, R.M. (2010). The role of intentional self regulation, lower neighborhood ecological assets, and activity involvement in youth developmental outcomes. Journal of Youth and Adolescence, 3977), 783-800. doi: 10.1007/s10964-010-9549-y 
Zaff, J.F., Kawashima-Ginsberg, K., \& Lin, E.S. (2011). Advances in civic engagement research: Issues of civic measures and civic context. In R.M. Lerner, J.V. Lerner, \& J.B. Benson (Eds.), Advances in child development and behavior. (pp.271-306). London, England: Elsevier.

(c) Copyright of Journal of Youth Development $\sim$ Bridging Research and Practice. Content may not be copied or emailed to multiple sites or posted to a listserv without copyright holder's express written permission. However, users may print, download or email articles for individual use. 